\title{
THE MIND'S EYE: PICTURE AS NARRATIVE IN THOMAS HARDY'S A PAIR OF BLUE EYES
}

\author{
Dimitar Karamitev \\ Plovdiv University Paisii Hilendarski, Plovdiv, Bulgaria
}

\begin{abstract}
This paper focuses on Thomas Hardy's A Pair of Blue Eyes in discussing certain peculiarities of narration. The numerous descriptions of people and scenes in the book are examined as basic building blocks used by the architecturally trained novelist to carry vital narrative information. This decision is approached by way of utilising ideas from the realms of phenomenology, cinema and photographic theory to prove that in addition to carrying aesthetic merits, Hardy's descriptions are intricate data containers that reflect how the human mind processes experience.
\end{abstract}

Keywords: perception, scene, picture, Thomas Hardy, mind's eye, narrative

\section{Article history:}

Received: 5 October 2021

Reviewed: 10 November 2021

Accepted: 30 November 2021

Revised: 17 December 2021

Published: 30 December 2021

Copyright (C) 2021 Dimitar Karamitev

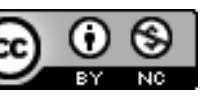

This open access article is published and distributed under a CC BY-NC 4.0 International License which permits non-commercial use, distribution, and reproduction in any medium, provided the original author and source are credited. Permissions beyond the scope of this license may be available at dimitarkaramitev@uni-plovdiv.bg. If you want to use the work commercially, you must first get the authors' permission.

Citation: Karamitev, D. (2021). The Mind's Eye: Picture as Narrative in Thomas Hardy's "A Pair of Blue Eyes". English Studies at NBU, 7(2), 261-273. https://doi.org/10.33919/esnbu.21.2.8

Dimitar Karamitev, MA, is a PhD student and a part-time assistant at the Faculty of Languages and Literature, Plovdiv University Paisii Hilendarski, Plovdiv, Bulgaria. His current research interests concern the balance between historicity and fictionality in the novels of Thomas Hardy, as well as the interplay between literature and visual arts.

E-mail: dimitarkaramitev@uni-plovdiv.bg

https://orcid.org/0000-0002-3627-7592 
The present academic undertaking examines A Pair of Blue Eyes - one of Thomas Hardy's early novels - from the point of the narrative technique employed. The aim is to provide sufficient evidence for the suggestion that Hardy's visually intense descriptions, in which his fiction abounds, serve a purpose higher than that of decoration. What is understood by this is that very often the writer resorts to meticulously crafted delineations of people and scenes that seem to render a picture before the eyes of readers which is there not only for aesthetic fascination but also to carry important narrative information. To support these claims, pertinent studies by authors such as Wolfgang Iser, Paul Ricoeur, Sergei Eisenstein, and Emmanuel Levinas are used.

\section{A Much-Needed Initiatory Glimpse}

In his preface, Hardy referred to A Pair of Blue Eyes as 'an imaginary history of three human hearts... found... a fitting frame for its presentation' (Hardy, 2009, p. 3). The concept of a book as a framed history may have to do with his infatuation with the arts of painting and photography, but it is also pertinent to Wolfgang Iser's ideas about the interaction between the fictive and the imaginary (Iser, 1993) - Hardy's imagination picked and choose elements from stories of real life and combined them with other ideas of his which resulted in a fictive story framed by the novel's limitations. A frame is like a container and a container has specifications that limit what is stored inside. These restrictions, in this case, facilitate a higher degree of concreteness of the imaginary so that when placed in a container (frame) it ferments into the fictive. Hardy's method of visual storytelling may result from the aforesaid fascination with pictures as it is known that 'he made use of every opportunity which the International Exhibition of that year [1862] and public and private galleries afforded to extend his knowledge of the various schools of art' (Gibson, 1999, p. 9). An article from 1886 makes it known that Hardy's own home at Max Gate, constructed by himself, was made so that its location affords a particular optical effect at sunrise in the eyes of beholders in the vicinity, as well as that the windows therein have been placed with an awareness of what can be seen from within and without - the architect-novelist arranged some of them so as to frame certain views of the environment (pp. 20-21). These influences shaped this technique which is not restricted to the current book but appears in one way or another in other novels (such as the episode in Desperate Remedies where Cytherea's father dies as she is contemplating the tragedy from a window) and poems (as 
in Outside the Window where the hero obtains vital information about his sweetheart by seeing and hearing her interaction with her mother concerning him through a window).

\section{Patterns of Perception}

To get a more concrete understanding of what is meant by visually intense descriptions, one must spend quite some time selecting from numerous examples. This investigation contains a few noteworthy ones. On the first pages of $A$ Pair of Blue Eyes (Hardy, 2009, pp. 21-22), one stumbles upon a curious episode with two main characters in which the readers witness Stephen's developing tender feelings for Miss Elfride as he is contemplating her features. The used language can not only articulate this fascination but also disclose important ideas related to the way the author builds his narrative and the manner in which, he believes, human perception works.

\section{The Mind's Eye: Receptacle and Agent of Perceptions}

The episode mentions a man's 'mind's eye' which contains 'a permanent impression' left by a woman in a 'scene' (p. 21). Judging from the context, this 'eye' could refer to that part of the human brain which deals with the perception of visual imagery or works by means of such imagery. In other words, 'the mind's eye' appears to function as a processor and an archival repository that keeps images on 'the pages of his memory' (p. 21). Then follow more details revealing the essence of the recorded - the narrator explains it has an 'attitude and accessories' as in a Mediaeval illumination (p. 21). From this, two suggestions may be made, one being that the recorded is remembered by means of fragmentary pieces of information relating to the object (attributes) and that these images carry some treasured spiritual value as is the case with ecclesiastical illustrations. As regards these attributes, they appear to be like the 'clues that guard against forgetting' Ricoeur uses in his definition of the word reminding - they resemble 'signposts' that 'guard against forgetting in the future' (Ricoeur, 2004, p. 38). The next few paragraphs exemplify some of these signposts - the character's profile, dress, face, hands, and so on. So, the relationship between the object portrayed and 'the mind's eye' has a metonymic flavour and shows reverence in contemplation.

\section{Capturing Perceptions as Images}

The ideas about human memories being stored in the form of images are old. Paul Ricoeur examines them in his Memory, History, Forgetting. He asks 'Do we not speak of what 
we remember, even of memory as an image of the past? The problem is not new: Western philosophy inherited it from the Greeks and from their variations on the term eikon' (Ricoeur, 2004, p. 44). He mentions Socrates's ideas that when we record perceptions there is a scribe accompanied by a craftsman who is a painter and follows what the scribe writes, providing illustrations (p. 14). This paper makes no attempt to explain this complex philosophical issue but it aims to show that Hardy, intentionally or not, gives voice to this phenomenon which means that his descriptions are tinged with phenomenological sensibilities. Also of utmost importance is the name of the image in question - 'a permanent impression'. On the one hand, this could refer to an everyday use as in an idea or opinion of what someone is like ("impression", 2021). On the other hand, considering the specific focus of this analysis and the special attention paid to visual phenomena on behalf of the narrator, one could suppose another more peculiar use of the word. In his book on theories of photography, Peter Geimer observes that some scientists involved in the early development of photography (Henry Talbot and Dominique Arago) used the word 'impression' ('empreinte') to denote a photograph as an image stamped onto paper by light and fixed there by chemicals (Geimer, 2011, p. 21). So, if a person's memory is like a book, drawing on the use of 'pages of his memory', then images are likely to be captured on their surface just as photographs are captured on various surfaces, including paper. Thus, one's memory or part of it can be seen as a photo album. In a discussion by F. B. Pinion on Hardy and pictorial art, a comment is made on 'the modes of perceiving different art forms' 'pictures emerge as we read, and can be stored in the memory; or a few selected features can be so presented that an impression of the whole is flashed upon the 'inward eye" (1977, p. 18). This seems to be the case with the examined fragment. Readers are presented with a scene that is to be stored in the memory of one of the characters in it, and the strong impression is dissected or explained in terms of certain features subjectively chosen by the beholder. Another notable moment in this episode is where the text reads 'Miss Elfride's image chose the form in which she was beheld...' (Hardy, 2009, p. 21) suggesting that the image has been created of its own accord and not because someone has conceived to take it. This corresponds to one of the earliest understandings of the photographic process. Talbot and later Andre Bazin believed that a photograph came into being on its own and the 'artist' was there only to place the camera before the subject and leave it time to be exposed as long as necessary, and Bazin, adding some details, has stated that the photographer's role should be seen in choosing the subject and composition, and the 
premediated impact (probably referring to the decision at what moment to initiate the act of capturing) (Talbot \& Bazin in Geimer, 2011, pp. 75, 79). At the time Hardy wrote this novel he might have been familiar with Talbot's ideas and used this phrasing to illustrate a parallel between processes in nature - photography (possible because of the rules of physics) and human perception (which happens according to natural rules which could possibly be explained by science). It is not known how interested in photography Hardy was but it has been documented that he and Hermann Lea, who produced 243 photographs of Wessex and had them printed in a guidebook called Thomas Hardy's Wessex, were close friends and Hardy helped him with the text and instructions about the locations of this fictional realm, also accompanying the photographer (Gibson, 1999). This means that Hardy was acquainted with photography in a not so distanced way, hence the potential interest in this art and what pertains to it. Additionally, one guest at Max Gate recalled that during his visit in 1910, in Hardy's drawing-room there was 'a full selection of photographs, scattered here and there' (Gibson, 1999, p. 91) which shows that the writer was interested in this art.

\section{Structure of Recorded Perceptions and Cinematic Sequences of Images}

One writer who has discussed Hardy's relations to visual arts has written that 'For Hardy, the visual image, whether a slight sketch of his own or a canvas by Rembrandt, acted as a kind of reservoir of ideas and feelings' (Bullen, 2009, p. 220). Thus, it seems that there exists something like a Chinese-box structure - one's mind is a container that holds images, and these images have their own contents. The latter could be emotions, feelings, or crucial moments that carry a particular significance. This structure also suggests synecdochical relations (part-whole) between the images that our minds hold and the things they point to. Perception suggests framing, focusing, and fixing of an object or event - to capture at least partially what is ever fleeting so that it can be played back, appreciated, and understood. Moving on, the reader finds out that Elfride's form was 'beheld during these minutes of singing' (Hardy, 2009, p. 21) which means two things - the time Stephen's mind was exposed to Elfride's image took more time than a regular photograph would require and that there was motion and sound. All this cannot but give a cinematic sensibility to the episode (moving pictures accompanied by sound). The narrative continues with a description of various details of the lady playing and singing - her dress, the colour of her neck, her face, hair, and hands. It must be pointed out that the word 'face' is repeated many 
times on these initial pages (pp. 21-22) that it cannot go unnoticed. In an article about Hardy from 1894 he wrote that when travelling 'I find myself observing my fellowpassengers and constructing the story of their lives from what I see in their faces' (Gibson, 1999, p. 45) which is an instance of the interplay between fictionality and historicity Hardy selected fragments from reality (passenger's faces in this case), his imagination processed them and then a final fictive product was born in writing. This attention to countenances is common to the entire book and to other novels by Hardy - very often characters' faces signify certain messages and emotions. Here, it is as if a camera is moving and recording a series of close-ups that feature important parts of Elfride and their interaction with the lighting and other pertinent objects such as the piano. The gluing together of these images could remind one of Sergei Eisenstein's montage theory of phenomena in film editing. He examines literary examples that are like predecessors to the methods employed for image-building in films. One of his reviews focuses on Homer and Lessing's analysis of the Iliad wherein the ancient poet is found to have used a device of forming an image by describing its key features in a logical order (Agamemnon's garments - each item is delineated in a sequence as if to dress the character before the eyes of readers) in which he finds an analogy to what cinematographers do when editing (Eisenstein, 2012).

David Lodge talked about Hardy as a cinematic novelist, giving examples from The Return of the Native, The Woodlanders, and the short story An Indiscretion in the Life of an Heiress - a remnant from his first novel, The Poor Man and the Lady (1999, p. 80, p. 87). Among discussing research by other scholars (Leon Edel) and suggesting that cinematic sensibilities are present in most realistic novelists of the 19th century (p. 78), Lodge delineated some differences between realistic novels and films, the former being freer as they can describe both visible and invisible phenomena hence a cinematic novelist is one who 'deliberately renounces some of the freedom of representation and report afforded by the verbal medium, who imagines and presents his materials in primarily visual terms, and whose visualisations correspond in some significant respect to the visual effects characteristic of film' (p. 80). It appears then that these cinematic peculiarities are not inherent only to these novels but also to the earlier A Pair of Blue Eyes. While it is difficult to say how much of his freedom Hardy renounced, it is clear that there is an emphasis on visual terms. In 1900 William Phelps visited Hardy and when discussing literature, the novel in question among other things, Phelps told Hardy 'I should have known by the 
structure of his novels that he had been a practising architect' and what he had in mind was plot structure, from what can be gathered from this account (Gibson, 1999, pp. 6364) but since there are pictures and scenes 'where more is meant than meets the eye' (Pinion, 1977, p. 22) everywhere in this book, it can be concluded that a literary picture is the main building block Hardy used to construct his products of literary architecture. The latter term was used by the novelist himself when talking about Victor Hugo's works - he saw them as 'the cathedrals of literary architecture' (Hardy, 1962, p. 311). All this shows that the architectural foundation of Hardy's novels is strong, and this is pertinent to the cinematic question as Eisenstein observed that in the construction of cathedrals one discerns other analogies between the philosophy of cinema and that of architecture because there exist specific sculptural groups or stops signifying the road to Calvary that have to do with the symbolism in ecclesiastical ceremonies (Eisenstein, 2012, pp. 147148). Additionally, he talked about Bernini's Baldachin and how its coats of arms are analogous to frames - script fragments with the same outline but different contents (details) that unfold an entire drama (p. 149). Hardy was occupied with architecture at a stage of his life and church-restoration was one area he was closely familiar with (Hardy, 1962, p. 31), therefore, he must have been acquainted with these symbolic peculiarities of architecture. Hence, it could be argued that this influenced him, subconsciously or not, and added to the architectural sensibilities of his works that could also carry a cinematic tinge. Other writers have seen similar features in Hardy's 'hugely agile manipulation of distance and perspective' in later novels such as Tess and have gone on to call them protocinematic (Bullen, 2009, p. 221). This further solidifies the sense of such properties in his writing and shows consistency in the use of a particular technique.

\section{Faces as Narratives}

Later in the novel one finds a scene that seems to have called into partiality an otherwise somewhat distanced narrator. He has become infatuated with the pair of blue eyes looking at Knight, another character Miss Elfride has feelings for, and describes them as worthy of a painting (Hardy, 2009, p. 150). The description of her look makes it obvious that her eyes and face are not simply aesthetically pleasing. The eyes express a trait of the character's behaviour that not only confirms her prettiness but also highlights the properties of her observation of the world - selective, deep, undisguised, and honest ( $p$. $150)$ and that is very important as regards the quality of narrative data. It may be argued 
that this narrative charge, the facts one learns about Elfride's perception of the person she is interested in, is what lends charm to her persona. In other words, Elfride is an interesting character because she exhibits certain behaviour which also greatly contributes to her appearance. This impression of the girl in the minds of the narrator and Knight seems to fit in one definition of impression Ricoeur mentions in his investigation of Plato's legacy regarding the questions of memory and recollection - 'an affection resulting from the shock of an event that can be said to be striking, marking' (Ricoeur, 2004, p. 14). Here, however, 'the shock' and 'striking' event that make this episode memorable are such in a good sense and are depicted in an intense fashion that highlight this scene as an act of falling in love.

The account continues with Knight's reception of this girl's exhibition of feeling. It is in two ways that the portrait painted with words by the narrator could be read. Firstly, it shows Elfride's face exhibiting awareness of the rashly but sincerely spoken words in 'the bright rose colour of her cheeks' which the falling sun saturates further (p. 151). Faces signifying feelings, messages, and emotions are indeed common with Hardy. One explanation may be what Levinas expressed in his Totality and Infinity, a work on 'patterns of experience as we live them through,' where he has pointed out that 'the face is a living presence; it is expression... The face speaks. The manifestation of the face is already a disclosure' $(1979$, pp. 12, 661). It is a manifestation of what happens in her mind that the reader witnesses here. On the other hand, this episode begins with 'Knight could not help looking at her' (Hardy, 2009, p. 150) which leads one to the assumption that what follows is a description of the way Elfride appears to him - someone who is not impartial to her. Sunset light is flattering but, in this case, it may only highlight the radiant charm this girl has for Knight. This corresponds to one of the picture types Pinion believes were used by Hardy - 'psychological' - 'a concrete and sometimes poetic way of expressing states of mind, feelings, and moods in the protagonists themselves' (1977, p. 25). Thus, Elfride's rose-coloured radiance has to do with light and the temperature of sunlight at a particular angle, and also with Knight's perception of her through rose-tinted spectacles, to use a more modern idiom. Again, this part of the book illustrates that a beautiful description of a character is not there to merely decorate. It clothes narrative

\footnotetext{
${ }^{1}$ It is important to note that this remark is a basic conclusion about body language. Levinas' discussion of "face" is a more complex philosophical idea developed later to talk about the presence of an Absolute Other, an interlocutor sine qua non who defines the Self.
} 
information of considerable importance in an appealing garment - one learns how characters' perceptions work and how their appearance signifies internal processes and feelings.

\section{History Viewed as Layers of Recorded Images}

Another truly memorable moment in the novel is Knight's hanging off a cliff in chapter XXII. The narrator mentions the grim features of the face of the cliff opposite the character himself who can behold: 'Nature's treacherous attempt to put an end to him' (Hardy, 2009, p. 199). As he hangs on, he discerns 'an imbedded fossil', a dead creature whose eyes 'were even now regarding him' (p. 200). What is present in this scene seems to illustrate eloquently Pinion's comment that 'Harmonization of landscape and situation is to be found in several of Hardy's novels' (1977, p. 29) - a dreary harmony exists as the unfriendly cliff, the fossilised organism, and surrounding environment are in accordance with Knight's peril.

The visual contact with the fossil triggers a peculiar thought process. But what is so special about this remnant of old life? Maybe the fact that it is a kind of an index that stands for more than the individual creature of a bygone epoch. The preserved fossil is a relic, just like an image could be. Something that projects into the viewer's mind a record of valuable information. Knight sees himself 'face to face with the beginning and all the intermediate centuries simultaneously' (Hardy, 2009, p. 200) and this could be read as a stream of consciousness in which 'images' follow one another - each signifying ages in the development of life on earth, flashing within seconds before Knight's inner eye. He has some knowledge of geology but more importantly - he thinks of large periods of time as images of scenes (p. 200). The latter is an important word in Hardy's works and it is difficult to define what exactly he meant by it - maybe it was something like a snapshot of a landscape. One recollection of a guest tells a story of how they went out of Max Gate, and upon reaching a high road and gazing at the panorama Hardy remarked that 'the scene interested him most as a record of history' after which he discussed the various tribes and peoples that had lived there and 'called the land a palimpsest, on which many a record had been written only to be erased to make place for another...' (Gibson, 1999, p. 92). Knight's confrontation with the geological cross section appears like a reading of this palimpsest. Also noteworthy is the fact that in an interview Hardy used the same term - 'The human mind is a sort of palimpsest, I suppose; and it's hard to say what records 
may not lurk in it' (p. 67). It would appear that this similarity exists because humans are parts of nature and this is what enables them to recognise and read the various layers of history. Elsewhere, Hardy uses a character to say 'Ay, life is a strange picter...' (Hardy, 2009 , p. 241) which shows a certain attitude of thinking about life. If life is a picture, then it is natural to think of different epochs of life as pictures or scenes. Additionally, the compression of time - 'Time closed up like a fan before him' (p. 200) - and the ensuing awareness of how petty life can be, depending on the point of reference, are triggered by this curious token with eyes that perceive nothing but incite reflection about what they have actually witnessed once in a primitive way and later continue to behold in this fossilized form. What happens is reminiscent of Ricoeur's thought that 'The brevity of human life stands out against the immensity of indefinite chronological time' (Ricoeur, 2004, p. 155). 'Chronological time' according to him 'designates the linear times of long periods: century, millennium, and so forth...' (p. 156) and the available geological strata facilitate the character's understanding and shock.

Knight's reaction is quite similar to the one Roland Barthes experienced when he saw a photograph of Napoleon's youngest brother and thought that he was looking at the eyes that had seen the Emperor (Barthes, 1981). It seems that a photograph shares similarities with a fossil - either way one is beholding something that has existed (considering only photographs that have not been manipulated) and while a fossil is the physical remains of the actual thing, a photograph also has a physical connection with its subject because it is the product of light rays bouncing off what one is photographing and falling into the photographic emulsion. The enlarged image from a negative/positive is indeed a copy but it also shares a physical connection with the emulsion that was originally touched by light. Moving back to the character in danger - Knight believes he is to die in the company of a primitive organism which, he feels, diminishes his dignity in a way. The man's thoughts also explore the intermingling of natural history and cultural history - seen in the combination of his historical and geological knowledge with the mention of 'the doomed Macbeth' (probably the Shakespearean character, not the historical Scottish king) (Hardy, 2009 , p. 200). This appears to be a mixture of historicity and fictionality - inherent to human perception of the past in general. People tend to look back, selecting only what their subjective stance sees in the past (an act of selection - a manifestation of the fictive) and mingle it with matters that have not occurred in actual history. Additionally, this sequence of imagery can be viewed as the phenomenon people say happens before one is about to 
perish - they view their life as if it were a short film. In this case, however, he sees the history of life on earth and a fragmentary picture of the future - Elfride living without him. Also noteworthy is the use of the term 'inner eye' (p. 201) which seems identical to the 'mind's eye' discussed above.

Another instance is the parting of Knight and Elfride, a sad moment after which the man witnesses a scene which 'was engraved for years on the retina of Knight's eye' (Hardy, 2009, p. 311). Here it is obvious that a landscape cannot be physically engraved on the eye but that the narrator is referring to that 'inner eye'. Once more the reader is reminded of the idea that one's mind works with mental images. In other words, what people look at influences their thought processes which use algorithms that make their minds picture (call out ideas for consideration in the form of images). Thus, to say that Hardy is a visual writer could be equal to talking of him as a writer who explores the human psyche.

\section{Light as an Instrument, Framing, Synecdoche}

One of the most recurrent motifs in the novel is the presence of light. A good example could be taken from the second half of the novel. Its role appears to be instrumental in the revelation of various objects but also of entire scenes - "The scratch of a striking light was heard... Stephen... saw in the summer-house a strongly illuminated picture' (p. 224). And what the picture consists of is Stephen's sweetheart in the close company of his friend and mentor Henry Knight (p. 225). In other words, light makes things visible. If things are visible, perception employs its most influential channel (there exist other channels but the visual seems to be the strongest with Hardy) and stories can be generated. In this case, the story of a heartbreak that is a fragment of the human relationships that unfold the novel's plot.

Further on, the three members of this novel's love triangle are found in a church's vault discussing the stories of the people buried there (one of them being Elfride's grandmother) and at a point Knight is caused to express his thoughts on the fragility of human life (pp. 244-245). The sight of the tombs initiates a more general discussion on existence which features several curious points. The human body and individual human life (depending how one interprets things) is a 'frame', a 'narrow cell' which can be overcome when one's mind is provoked into deep reflection and unlocks its huge capacity (p. 245). It follows then that Hardy's narrative technique of presenting events and characters as (parts of) scenes or pictures is as per this philosophy. Since one's existence 
happens within a frame, then it is natural that the writings concerning people and their life are presented in frames. This is in accordance with the logic implied in the previous discussion of synecdochical relations. It is important to mention that similar phenomena are also present in his poetry - Satires of Circumstance in Fifteen Glimpses (1911) features pieces that illustrate this. One writer has observed that 'the past returns through places, through objects of concrete physical value... whereby one recalls' various previous experiences (Rowland, 2014, p. 152). In other words, the presence of an item refers metonymically to something else which is usually bigger.

Toward the end of the book the narrator offers another noteworthy picture-related episode. After their estrangement, the two suitors of Elfride meet again. Stephen has a few pocket-books with various sketches among which there are some mediaeval figures. After some perusal, Knight notices 'a peculiarity' - all female saints have a feature in common 'That profile - how well Knight knew that profile' (Hardy, 2009, p. 331). In the conversation between the two men, it becomes obvious that Stephen has been unconsciously using the portrait of his beloved as a model in these images (p. 332). It can be argued that pictures have been used again as an intricate narrative technique. It is not the sketches that are important as plans for a stained-glass installation, but what they show beyond that - the fact that Stephen has not forgotten his sweetheart and has subconsciously professed his love for her in these drawings. It is interesting that Stephen himself has performed an act of fictionalizing - the man has taken something from his history (one must call it so for a moment despite the fact that it is a novel portraying an imaginary chain of events) and combined it, unconsciously, with other ideas to produce fictive pictures that carry a strong narrative charge in addition to their aesthetic merits.

\section{Conclusions}

It becomes clear that Hardy's A Pair of Blue Eyes employs a peculiarly visual narrative technique that carries phenomenological tinges with an interesting insight into the way human perception works. A path for future investigation could be the classification of all manifestations of this technique in Hardy's novels - the meaning of landscape, the importance of perspective, faces, or the use of ekphrasis. The Return of the Native, published approximately five years after A Pair of Blue Eyes, offers a lot in this respect. One could analyse its emphasis on the appearance of faces as an intricate way of plot-building - a character's countenance as a container of vital information. Alternatively, the use of 
perspective as a trigger of satires of circumstance is another question worthy of examination - the discussed characters become victims of circumstance or are saved from becoming such depending on what their perspective allows them to perceive.

\section{References}

Barthes, R. (1981). Camera Lucida: Reflections on Photography. (R. Howard, Trans.). Hill and Wang.

Bullen, J. B. (2009). Hardy and the Visual Arts. In K. Wilson (Ed.), A Companion to Thomas Hardy (pp. 210-222). John Wiley and Sons. https://doi.org/10.1002/9781444324211.ch14

Cambridge University Press. (2021). impression. Cambridge Dictionary. https://dictionary.cambridge.org/dictionary/english/impression

Eisenstein, S. (2012). Montazhat (Prof. V. Ignatovski, Trans.). Iztok-Zapad.

Geimer, P. (2011). Teorii na fotografiyata (Zh. Tsenova, Trans.). Iztok-Zapad.

Gibson, J. (Ed.). (1999). Thomas Hardy: Interviews and Recollections. Macmillan Press. https://doi.org/10.1007/978-1-349-27546-5

Hardy, E. F. (1962). The Life of Thomas Hardy: 1840-1928. The Macmillan Press. https://doi.org/10.1007/978-1-349-00286-3

Hardy, T. (2009). A Pair of Blue Eyes. Oxford University Press. https://doi.org/10.1093/owc/9780199538492.001.0001

Iser, W. (1983). The Fictive and the Imaginary. The Johns Hopkins University Press.

Levinas, E. (1979). Totality and Infinity. (A. Lingis, Trans.). Martinus Nijhoff Publishers. https://doi.org/10.1007/978-94-009-9342-6

Lodge, D. (1999). Thomas Hardy as a Cinematic Novelist. In L. St. John Butler (Ed.), Thomas Hardy after Fifty Years (pp. 78-89). The Macmillan Press. https://doi.org/10.1007/978-1-349-03219-8

Pinion, F. B. (1977). Thomas Hardy: Art and Thought. Macmillan Press. https://doi.org/10.1007/978-1-349-15765-5

Ricoeur, P. (2004). Memory, History, Forgetting. The University of Chicago Press. https://doi.org/10.7208/chicago/9780226713465.001.0001

Rowland, Y. (2014). Movable Thresholds: On Victorian Poetry and Beyond in Nineteen Glimpses. Plovdiv University Press. 